\title{
Proteomic screening of glucose-responsive and glucose non-responsive MIN-6 beta cells reveals differential expression of proteins involved in protein folding, secretion and oxidative stress
}

\author{
Paul Dowling ${ }^{1 *}$, Lorraine O'Driscoll ${ }^{1 *}$, Finbarr O'Sullivan ${ }^{1}$, Andrew Dowd $^{1}$, \\ Michael Henry ${ }^{1}$, Per Bendix Jeppesen ${ }^{2}$, Paula Meleady ${ }^{1 * *}$ and Martin Clynes ${ }^{1 * *}$ \\ ${ }^{1}$ National Institute for Cellular Biotechnology, Dublin City University, Dublin, Ireland \\ ${ }^{2}$ Department of Endocrinology and Metabolism C, Aarhus University Hospital, \\ Aarhus Sygehus THG, Aarhus, Denmark
}

\begin{abstract}
The glucose-sensitive insulin-secretion (GSIS) phenotype is relatively unstable in long-term culture of beta cells. The purpose of this study was to investigate relative changes in the proteome between glucose-responsive (low passage) and glucose non-responsive (high passage) murine MIN-6 pancreatic beta cells. The 2D-DIGE and subsequent DeCyder analysis detected 3351 protein spots in the $\mathrm{pH}$ range of 4-7. Comparing MIN-6(H) to MIN-6(L) and using a threshold of 1.2-fold, the number of proteins with a decrease in expression level was $152(4.5 \%)$, similar was $3140(93.7 \%)$ and increased 59 (1.8\%). From the differentially expressed proteins identified in this study, groups of proteins associated with the endoplasmic reticulum (ER) and proteins involved in oxidative stress were found to be significantly decreased in the high-passage (H passage) cells. These proteins included endoplasmic reticulum protein 29 (ERp29); 78-kDa glucoserelated protein, (GRP78); 94-kDa glucose-related protein (GRP94); protein disulphide isomerase; carbonyl reductase 3; peroxidoxin 4 and superoxide dismutase 1 . These results suggest that nonGSIS MIN-6 cells do not have the same ability/capacity of glucose-responsive MIN-6 cells to successfully fold, modify or secrete proteins and counteract the problems associated with oxidative stress.
\end{abstract}

\section{Keywords:}

DIGE / Endoplasmic reticulum / Glucose-Sensitive Insulin Secretion / MIN-6 beta cells / Oxidative stress

Correspondence: Dr. Paul Dowling, National Institute for Cellular Biotechnology, Dublin City University, Glasnevin, Dublin 9, Ireland

E-mail: paul.dowling@dcu.ie

Fax: +353-1-700-5484

Abbreviations: ERp29, 29-kDa ER protein; GSIS, glucose-sensitive insulin-secretion; GRP, glucose-related protein; $\mathbf{H}$ passage, high passage; L passage, low passage; LSCM, laser scanning confocal microscopy; PDI, protein disulphide isomerase; RNS, reactive nitrogen species; $\mathbf{R O S}$, reactive oxygen species

\section{Introduction}

Diabetes mellitus is a disabling disease that currently affects at least 170 million people worldwide and the incidence is growing at an alarming rate $[1,2]$. Cell replacement therapies are potential alternatives to the insulin injections currently employed to control blood glucose in diabetes, and it has been demonstrated that this condition may be cured, at least

* These authors contributed equally to this paper. 
on a temporary basis, by transplantation of pancreatic islets isolated from donor pancreas [3]. However, the shortage of human islet cells represents a limitation for large-scale use of islet transplantation to cure patients with diabetes. Alternative sources of beta cells with a suitably stable phenotype have yet to be defined [4]. A fundamental characteristic of suitable replacement cells is their ability to secrete mature insulin in response to physiological changes in blood levels of glucose and other nutrients (glucose-sensitive insulin secretion, GSIS). Unfortunately, studies of such cells by us [5] and others have indicated that this necessary regulated secretion is lost in beta cell lines such as MIN-6 with passaging of these cells in culture. A better understanding of the complex nature of GSIS is necessary to allow the prevention or correction of such problems in the future.

Beta cells are specialized for the synthesis of high levels of insulin; the correct folding of proinsulin in the ER is essential for the efficient production of insulin. Molecular chaperones are a specialized subset of proteins whose function is to assist other proteins in achieving proper folding in the ER. Many chaperones are heat shock proteins, that is, proteins expressed in response to elevated temperatures or other cellular stresses, and include 78-kDa glucose-regulated protein (GRP78), GRP58, GRP94, protein disulphide isomerase (PDI), calreticulin, 29-kDa ER protein (ERp29). Altered expression levels of several proteins including GRP78, GRP94 and PDI have been shown to be associated with the pathophysiology of diabetes [6-11].

Oxidative stress, defined as a persistent imbalance between the production of highly reactive oxygen species (ROS) and/or reactive nitrogen species (RNS) and antioxidant defences is likely to be involved in progression of pancreatic beta cell dysfunction. In healthy beta cells, a balance of generating and neutralizing ROS and RNS establishes the redox homeostasis, which is important for normal cell function. Examples of ROS include charged species such as superoxide and the hydroxyl radical and uncharged species such as hydrogen peroxide. Beta cells are sensitive to ROS and RNS because they are low in free-radical quenching (antioxidant) enzymes such as catalase, glutathione peroxidase, and superoxide dismutase and this has also been shown to be greatly involved in the pathophysiology of diabetes $[12,13]$.

The aim of this study was to examine differential regulation of the proteome associated with continuous culture of MIN-6 cells and corresponding loss of GSIS phenotype to enable future development of potential methods whereby relevant beta cell functions could be preserved in long-term culture [14-16].

\section{Materials and methods}

\subsection{MIN-6 culture}

MIN-6 cells (generously donated by Dr. Yamamoto, Kumamoto University school of Medicine, Japan) were grown in
DMEM containing 20\% heat-inactivated FCS and were cultured at $37^{\circ} \mathrm{C}$ with $5 \% \mathrm{CO}_{2}$. Routine sterility checks, including screening for Mycoplasma, indicated that the cells were clear of contamination. MIN-6 (H passage) at passage 40 cells was established by sub-culturing MIN-6 (L passage) cells from passage 18 , as previously described [5].

\subsection{GSIS analysis of MIN-6 cells}

MIN-6 cells were seeded at $2 \times 10^{5}$ cells/well in a 24-well plate, and were allowed to grow for $72 \mathrm{~h}$ prior to the GSIS assay. Following this, $1 \times$ KRB (Krebs-Ringer bicarbonate) buffer was prepared from an aliquot of frozen $10 \times$ stock (36.525 g NaCl, $2.2 \mathrm{~g} \mathrm{KCl}, 0.941 \mathrm{~g} \mathrm{CaCl}_{2}+2 \mathrm{H}_{2} \mathrm{O}, 1.22 \mathrm{~g}$ $\mathrm{MgCl}_{2}+6 \mathrm{H}_{2} \mathrm{O}$, 29.8g HEPES dissolved in $500 \mathrm{~mL} \mathrm{H} \mathrm{H}_{2} \mathrm{O}$ ). BSA was added to a final concentration of $0.1 \%$, and the KRB-BSA was pH-adjusted to 7.36 at $19^{\circ} \mathrm{C}$ with $1 \mathrm{~mol} / \mathrm{L}$ $\mathrm{NaOH}$. This solution was incubated for $30 \mathrm{~min}$ at $37^{\circ} \mathrm{C}$ and $5 \% \mathrm{CO}_{2}$. Glucose concentrations of $0,3.3,10,16.7$, and $26.7 \mathrm{mmol} / \mathrm{L}$ were prepared in the conditioned $1 \times \mathrm{KRB}$ and were subsequently placed at $37^{\circ} \mathrm{C}$ and $5 \% \mathrm{CO}_{2}$ for $30 \mathrm{~min}$. MIN-6 cells to be analyzed were rinsed (twice) in $1 \times \mathrm{KRB}$ and were equilibrated at $3.3 \mathrm{mmol} / \mathrm{L}$ glucose for $30 \mathrm{~min}$ at $37^{\circ} \mathrm{C}$. After equilibration, the glucose-containing stimulation media were added $(1 \mathrm{~mL} /$ well $)$, incubated at $37^{\circ} \mathrm{C}$ and $5 \%$ $\mathrm{CO}_{2}$ for $60 \mathrm{~min}$. The GSIS assay was then terminated by placing the plate on ice. Conditioned medium $(500 \mu \mathrm{L})$ was removed from each well, placed in an ice-cold Eppendorf tube, centrifuged at $2500 \mathrm{rpm}$ for $5 \mathrm{~min}$ and $200 \mu \mathrm{L}$ of the supernatant was removed for analysis by (pro)insulin ELISA (Mercodia, 10-1124-10) following the manufacturer's instructions.

\subsection{Immunofluorescence}

MIN-6(L) and MIN-6(H) were plated on glass chamber slides (NUNC) and cultured at $37^{\circ} \mathrm{C}, 5 \% \mathrm{CO}_{2}$ for 5 days before analysis. Cells were washed in PHEM buffer (PIPES $60 \mathrm{mMol} / \mathrm{L}, \mathrm{HEPES} 25 \mathrm{mMol} / \mathrm{L}$, EGTA $10 \mathrm{mMol} / \mathrm{L}, \mathrm{MgCL}_{2}$ $2 \mathrm{mMol} / \mathrm{L}$ ) and fixed in $4 \%$ paraformaldehyde, $0.5 \%$ gluteraldehyde in PHEM for $20 \mathrm{~min}$ at room temperature. Cells were permeabilized with $0.1 \%$ Triton X-100 in PHEM. Free aldehyde groups were reduced with $0.1 \% \mathrm{w} / \mathrm{v}$ sodium borohydride in PBS. Cells were blocked for $30 \mathrm{~min}$ in $10 \%$ normal goat serum (NGS) in PHEM at room temperature followed by overnight incubation with $10 \mu \mathrm{g} / \mathrm{mL}$ rat anti-insulin (R\&D Systems) in PHEM/0.1\% NGS. Cells were incubated with $8 \mu \mathrm{g} / \mathrm{mL}$ goat anti-rat IgG 488 Alexa Fluor (Molecular Probes; A11006) in 0.1\% NGS in PHEM for $1 \mathrm{~h}$ at room temperature. Nuclei were counterstained by incubating slides at room temperature for $20 \mathrm{~min}$ with $1 \mathrm{mg} / \mathrm{mL}$ RNase A (Sigma Aldrich) followed by staining for $5 \mathrm{~min}$ with propidium iodide (Biotium). The slides were examined by confocal laser scanning microscopy using a Leica TCS AOBS. 


\subsection{Sample preparation and protein labelling}

Cells at approximately $80 \%$ confluence were washed twice in PBS, twice in sucrose buffer before being lysed in buffer containing (4\% w/v CHAPS, $7 \mathrm{M}$ Urea, $2 \mathrm{M}$ thiourea, $10 \mathrm{mM}$ Tris- $\mathrm{HCl}, 5 \mathrm{mM}$ magnesium acetate $\mathrm{pH} 8.5$ ), and then homogenized by passing through a 25 -gauge needle six times. Insoluble material was removed by centrifugation at $14000 \mathrm{rpm}$ for $20 \mathrm{~min}$ at $10^{\circ} \mathrm{C}$. Protein concentration was determined using the BSA protein assay kit (Bio-Rad).

Cell lysates were labelled with N-hydroxy succinimidyl ester-derivatives of the cyanine dyes Cy2, Cy3, and Cy5 following the protocol described previously. Typically, $50 \mu \mathrm{g}$ of lysate was minimally labelled with 200 pmol of either Cy3 or Cy5 for comparison on the same 2-D gel. Labelling reactions were performed on ice in the dark for $30 \mathrm{~min}$ and then quenched with a 50-fold molar excess of free lysine to dye for $10 \mathrm{~min}$ on ice. A pool containing equal amounts of all samples was also prepared and labelled with Cy2 to be used as a standard on all gels to aid image matching and cross-gel statistical analysis. The Cy3 and Cy5 labelling reactions ( $50 \mu \mathrm{g}$ of each) from each lysate were mixed and run on the same gels with an equal amount $(50 \mu \mathrm{g})$ of Cy2-labeled standard [17].

\subsection{Protein separation by 2-DE and gel imaging}

Immobilized 24-cm linear pH gradient (IPG) strips, $\mathrm{pH}$ 4-7, were rehydrated in rehydration buffer (7 M urea, $2 \mathrm{M}$ thiourea, 4\% CHAPS, 0.5\% IPG buffer, 50 mM DTT) overnight, according to the manufacturers guidelines. IEF was performed using an IPGphor apparatus (GE Healthcare) for $40 \mathrm{kV} \mathrm{h}$ at $20^{\circ} \mathrm{C}$ with resistance set at $50 \mathrm{~mA}$. Strips were equilibrated for $20 \mathrm{~min}$ in $50 \mathrm{mM}$ Tris- $\mathrm{HCl}, \mathrm{pH} \mathrm{8.8,6} \mathrm{M}$ urea, 30\% v/v glycerol, $1 \% \mathrm{w} / \mathrm{v}$ SDS containing $65 \mathrm{mM}$ DTT and then for $20 \mathrm{~min}$ in the same buffer containing $240 \mathrm{mM}$ iodoacetamide. Equilibrated IPG strips were transferred onto $18 \times 20$-cm $12.5 \%$ uniform polyacrylamide gels poured between low fluorescence glass plates. Strips were overlaid with $0.5 \% \mathrm{w} / \mathrm{v}$ low melting point agarose in running buffer containing bromophenol blue. Gels were run using the Ettan Dalt 6 apparatus (GE Healthcare) at $2.5 \mathrm{~W} /$ gel for $30 \mathrm{~min}$ and then $100 \mathrm{~W}$ total at $10^{\circ} \mathrm{C}$ until the dye front had run off the bottom of the gels. All the images were collected on a Typhoon 9400 Variable Mode Imager (GE Healthcare). Statistics and quantitation of protein expression were carried out in DeCyder software (GE Healthcare).

\subsection{Spot digestion and MALDI-TOF analysis}

Excision of protein spots, trypsin digestion, and protein identification by MS analysis using an Ettan MALDI-TOF Pro instrument from Amersham Biosciences was performed according to an established methodology [18]. Preparative gels containing $300 \mu \mathrm{g}$ of protein were fixed in $30 \% \mathrm{v} / \mathrm{v}$ methanol, $7.5 \% \mathrm{v} / \mathrm{v}$ acetic acid overnight and washed in water, and total protein was detected by post-staining with
SyproRuby dye (Molecular Probes) for $3 \mathrm{~h}$ at room temperature. Excess dye was removed by washing twice in water, and gels were imaged using a Typhoon 9400 Variable Mode Imager (GE Healthcare) at the appropriate excitation and emission wavelengths for the stain. The subsequent gel image was imported into the BVA module of DeCyder software and was matched to images generated from DIGE analysis. Spots of interest were selected and confirmed using this software for subsequent picking using an Ettan Spot Picker. Gel plugs were placed into a presilconized $1.5-\mathrm{mL}$ plastic tube for destaining, desalting and washing steps. The remaining liquid above the gel plugs was removed and sufficient ACN was added in order to cover the gel plugs. Following shrinkage of the gel plugs, ACN was removed and the protein-containing gel pieces were rehydrated for 5 min with a minimal volume of $100 \mathrm{mM}$ ammonium bicarbonate. An equal volume of ACN was added and after 15 min of incubation the solution was removed from the gel plugs and the samples were dried for $30 \mathrm{~min}$ using a vacuum centrifuge. Individual gel pieces were then rehydrated in digestion buffer (12.5 ng trypsin per $\mu 1$ of $10 \% \mathrm{ACN}, 40 \mathrm{mM}$ ammonium bicarbonate) to cover the gel pieces. More digestion buffer was added if all the initial volume had been absorbed by the gel pieces. Exhaustive digestion was carried out overnight at $37^{\circ} \mathrm{C}$. After digestion, the samples were centrifuged at $12000 \times \mathrm{g}$ for 10 min using a bench top centrifuge. The supernatant was carefully removed from each sample and placed into clean and silconized plastic tubes. Samples were stored at $-80^{\circ} \mathrm{C}$ until analysed by MS. For spectrometric analysis, mixtures of tryptic peptides from individual samples were desalted using Millipore C-18 Zip-Tips (Millipore) and eluted onto the sample plate with the matrix solution $(5 \mathrm{mg} / \mathrm{mL}$ CHCA in $50 \%$ ACN/0.1\% TFA v/v). Mass spectra were recorded using the MALDI TOF instrument operating in the positive reflector mode at the following parameters: accelerating voltage $20 \mathrm{kV}$; and pulsed extraction: on (focus mass 2500). Internal and external calibration was performed using trypsin autolysis peaks at $m / z$ 842.50, $m / z 2211.104$ and Pep4 mix, respectively. The mass spectra were analysed using MALDI evaluation software (GE Healthcare), and protein identification was achieved with the PMF Pro-Found search engine.

\subsection{Statistical analysis}

Two-sided, Student's $t$-tests were used to analyze differences in protein levels between MIN-6(L) cell lysates and MIN-6(H) cell lysates. A $p$-value of less than 0.01 was considered statistically significant.

\section{Results}

\subsection{Morphology of MIN-6 (L) and (H)}

MIN-6(L) and MIN-6(H) cells were cultured at $37^{\circ} \mathrm{C}, 5 \% \mathrm{CO}_{2}$ for 5 days prior to analysis using phase contrast light mi- 
croscopy. This contrast-enhancing optical technique used to produce high-contrast images of transparent specimens, was performed at $10 \times, 20 \times$ and $40 \times$ magnification by imagining the living, unfixed cells using a Nikon Optiphot microscope with phase contrast rings. Phase contrast light microscopy indicates that MIN-6(L) cells that are glucoseresponsive tend to grow closely together, forming discrete colonies (Fig. 1A), whereas MIN-6(H) cells, shown in (Fig. 1B), which have lost their glucose-responsiveness with culturing, appear to be more disperse, stretched cells.

\subsection{Immunofluorescence}

Laser scanning confocal microscopy (LSCM) analysis of (Fig. 1C) MIN-6(L) and (Fig. 1D) MIN6-(H) cells indicates insulin (green staining) to be located in cytoplasmic granules. The numbers and localisation of insulin granules are apparently not significantly different between these two cell populations. Nuclei were stained with propidium iodide (red staining).

\subsection{GSIS from MIN-6 $\mathrm{H}$ passage and L passage cells}

As shown in Fig. 2, MIN-6 (L) cells secrete insulin in a glucose-regulated manner, with an approximately 5.5-fold increase in secreted product between 3.3 and $26.7 \mathrm{mM}$ glucose. In contrast to this, MIN6 $(\mathrm{H})$ cells do not show a functional GSIS response, i.e. the basal secretion of insulin from these cells is not influenced by the glucose content of their environment.
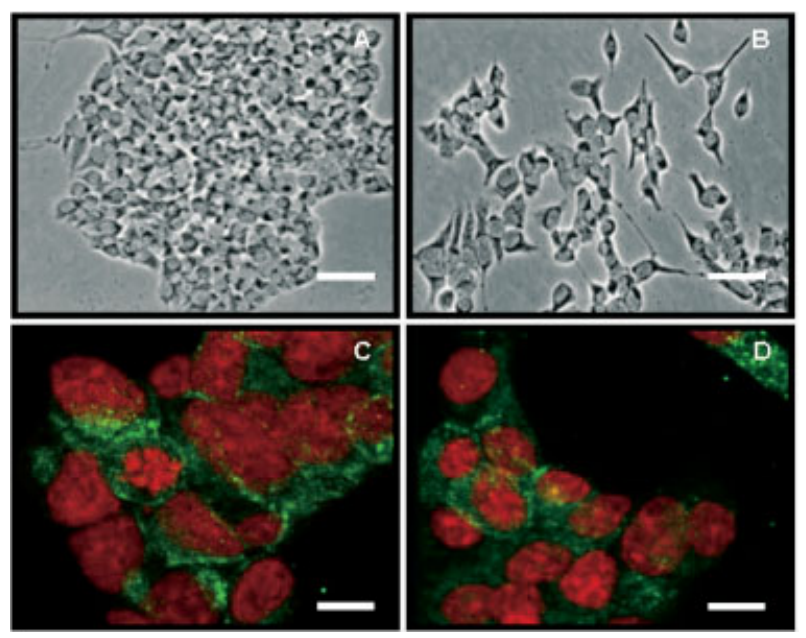

Figure 1. Phase contrast light microscopy indicates that MIN-6(L) cells, which are glucose-responsive tend to grow closely together, forming discrete colonies (A), whereas MIN-6(H) cells, shown in (B), which have lost their glucose-responsiveness with culturing, appear to be more disperse, stretched cells. Scale bar $25 \mu \mathrm{m}$. LSCM analysis of (C) MIN-6(L) and (D) MIN6-(H) cells indicates insulin (green staining) to be located in cytoplasmic granules. The numbers and localisation of insulin granules are apparently not significantly different between these two cell populations. Nuclei were stained with propidium iodide (red staining). Scale bar $10 \mu \mathrm{m}$.

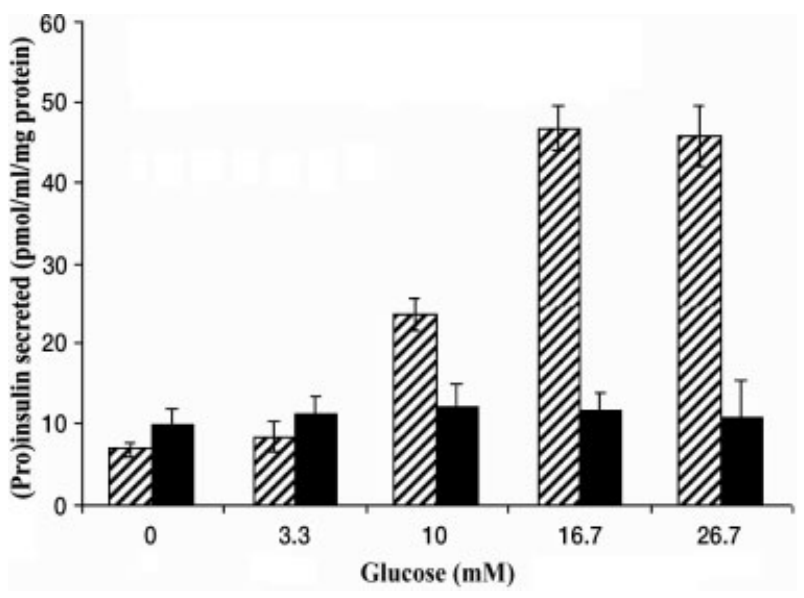

Figure 2. MIN-6(L) cells secrete (pro)insulin in a glucose-regulated manner (hashed bars). This regulated secretion is no longer apparent following long-term culture/passaging of $\mathrm{MIN}-6(\mathrm{H})$ cells (black bars). Results represent means \pm SD from three experiments.

\subsection{Effects of continuous passaging of MIN-6 cells on protein expression patterns using 2D-DIGE (IEF pH range 4-7)}

Fifty micrograms of protein from each sample was labelled with Cy2, Cy3, or Cy5. Eight samples each from MIN-6(L) and MIN-6(H) (experimental design included independent biological samples/biological replicates) were labelled with Cy3 and Cy5, respectively. All 16 samples employed in the experiment were used in the Cy2-labelled internal pooled standard. Samples were combined and separated by 2-DE. For DeCyder image analysis, the differential in-gel analysis mode of DeCyder was first used to merge the Cy2, Cy3, and Cy5 images for each gel and to detect spot boundaries for the calculation of normalized spot volumes/protein abundance. At this stage, features resulting from non-protein sources, namely dust particles and scratches were filtered out. The analysis was used to rapidly calculate abundance differences between samples run on the same gel. The biological variation analysis mode of DeCyder was then used to match all pair wise image comparisons from difference in-gel analysis for a comparative cross-gel statistical analysis. Operator intervention was required at this point to set landmarks on gels for more accurate cross-gel image superimposition. Comparison of normalized Cy3 and Cy5 spot volumes with the corresponding Cy2 standard spot volumes within each gel gave a standardized abundance. This value was compared across all gels for each matched spot and a statistical analysis was performed.

A total of 3351 protein spots were detected in the $\mathrm{pH}$ range of 4-7. Comparing MIN-6(H) to MIN-6(L) and using a threshold of 1.2-fold, the number of proteins with a decrease in expression level was (4.5\%), similar 3140 (93.7\%) and increased 59 (1.8\%). From the data generated, it is clear that a 
significant number of proteins are differentially expressed between MIN-6(H) cell lysates and MIN-6(L) cell lysates. The migration patterns and exact location of the identified proteins that were found to be differentially expressed are shown (Fig. 3).

The 35 differentially expressed proteins passed certain criteria for inclusion in the list, including appearing in all gels, a $p$-value of less than 0.01 and for protein identification an expectation value of 0.00 (Table 1). An expectation value of zero denotes a perfect match; an expectation value of 0.01 indicates a $1 \%$ chance that the identification is random. All reported identifications in this study have an expectation value of 0.00 . The 35 differentially expressed proteins identified were found to have a broad range of functions, including chaperone activity, DNA binding, signal transduction, extracellular structure, growth factors, cell motility and metabolism/catabolism. From the data acquired, it is clear that the majority of proteins identified in this study is involved in chaperone activities and in metabolism/catabolism (Fig. 4).

Four differentially expressed proteins associated with the ER and specifically involved in chaperone activity, namely GRP94, GRP78, PDI and ERp29 were identified. The abundance of all four proteins was found to be significantly decreased in MIN-6(H) compared to MIN-6(L).

GRP94 (2.73-fold decrease) is a resident protein of the ER and is induced by the accumulation of unfolded proteins. The GRP78/BiP (2.91-fold decrease) belongs to the family of $\sim 70-\mathrm{kDa}$ heat shock proteins (HSP70) and is associated with newly synthesised proteins. PDI involved in disulphide-bond formation and isomerization, as well as the reduction of disulphide bonds in proteins was found to be 2.44 decreased in $\mathrm{H}$ passage compared to L passage cells. A recently characterized protein, ERp29 (2.34-fold decrease) is closely related to these chaperone proteins and appears to be up-regulated during ER stress conditions. This soluble protein is localized to the lumen of the ER in all mammalian cells (Table 1 and Fig. 5).

The majority of proteins identified was found to be involved in metabolism/catabolism. Of these proteins carbonyl reductase 3, peroxidoxin 4 and superoxide dismutase are known to have similar functions as antioxidant enzymes and protecting cells from free radical-mediated damage. Carbonyl reductase plays a unique role in the detoxification of reactive aldehydes derived from lipid peroxidation and was found to display a 3.54-fold decrease in H passage cells. Peroxiredoxin 4 (2.77-fold decrease) represents a member of a recently discovered family of antioxidant proteins. Superoxide dismutase 1 (1.97-fold decrease) is a very well documented antioxidant that catalyses the conversion of superoxide radicals to molecular oxygen. Their function is to destroy the radicals that are normally produced within cells and are toxic to biological systems (Table 1 and Fig. 5).

Analysis of the protein expression using DeCyder software provided 3-D simulation of the protein spots, allowing an objective view for the comparison of spot intensity

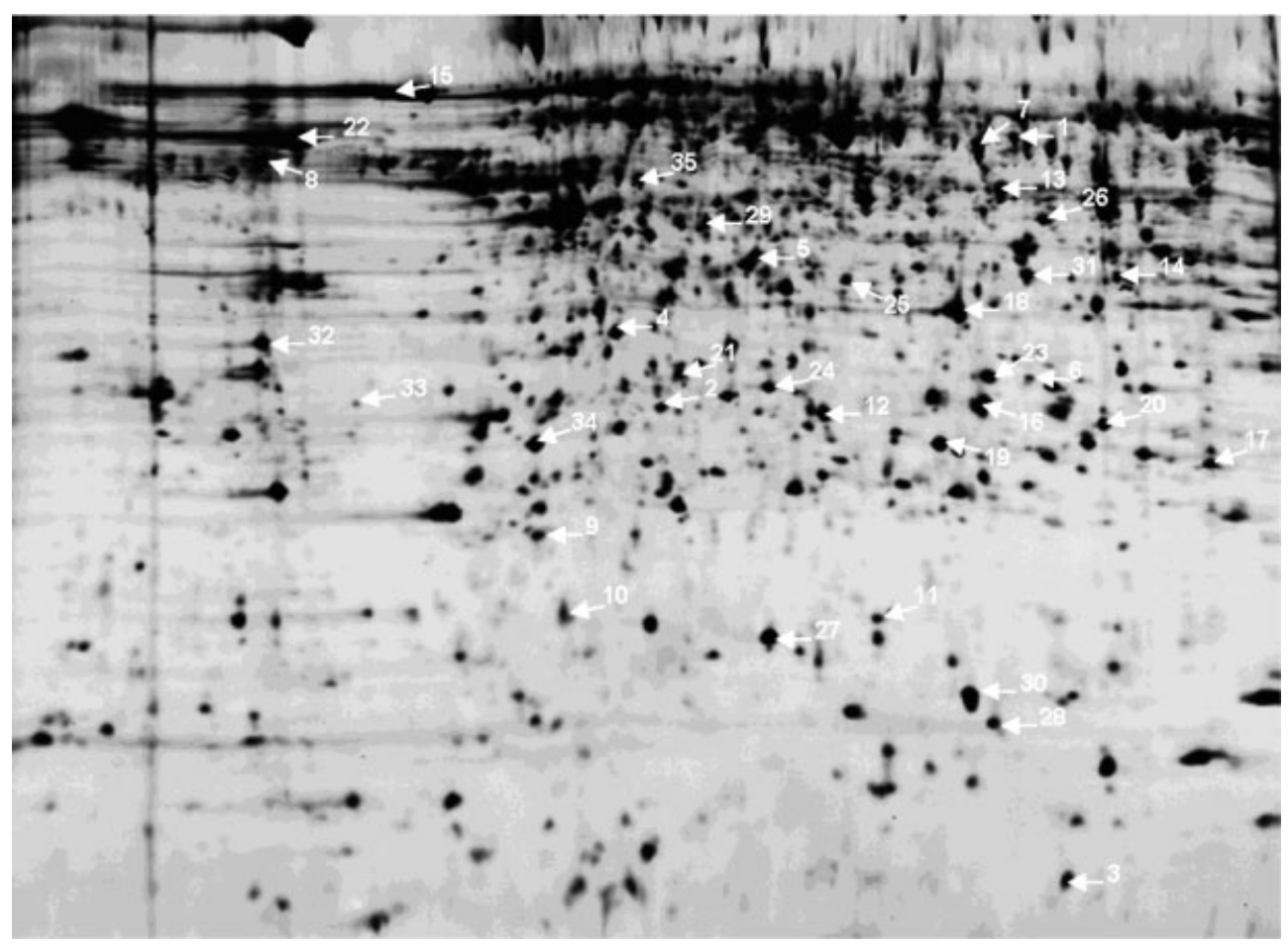

Figure 3. The 2D-DIGE gels showing the fluorescent signal obtained from $150 \mu \mathrm{g}$ of MIN-6 lysates and analyzed using minimal labelling. The 2D-DIGE gel shows the separation of approximately 3500 proteins by molecular weight and pl. Displayed on the gel are the locations of the 35 differentially expressed proteins identified in this study. 
Protein Function

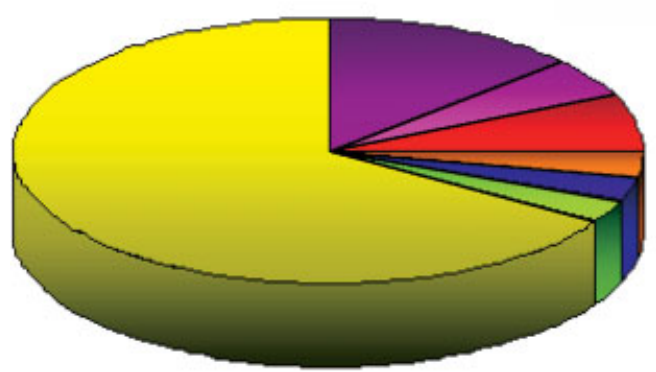

- Chaperone activiy $13 \%$

a DNA binding protein $\mathbf{5 \%}$

a Signal Transduction 7\%

a Extracellular structure 3\%

- Growth Factor 3\%

口 Cell motility $3 \%$

口 Metabolism/Catabolism 66\%
Figure 4. Pie chart displaying the functions of the 35 differentially expressed proteins in $\mathrm{MIN}-6(\mathrm{H})$ cells versus $\mathrm{MIN}$ $6(\mathrm{~L})$ cells.

Table 1. Table showing identification, average ratio, $t$-test scores, theoretical molecular weight (Mw), theoretical $\mathrm{p} /, \%$ coverage and expectation values for each of the 35 differentially expressed proteins in MIN-6(H) cells versus MIN-6(L) cells

\begin{tabular}{|c|c|c|c|c|c|c|c|}
\hline $\begin{array}{l}\text { Spot } \\
\text { number }\end{array}$ & Name & $t$-test & $\begin{array}{l}\text { Av. } \\
\text { ratio }\end{array}$ & $\begin{array}{l}\text { Theoreti- } \\
\text { cal p } /\end{array}$ & $\begin{array}{l}\text { Theoreti- } \\
\text { cal Mw }\end{array}$ & $\begin{array}{l}\% \\
\text { Coverage }\end{array}$ & $\begin{array}{l}\text { Expecta- } \\
\text { tion value }\end{array}$ \\
\hline 1 & 3-Phosphoglycerate dehydrogenase & 0,00087 & 2,65 & 6,1 & 57370 & $15,80 \%$ & 0 \\
\hline 2 & 6-Phosphogluconolactonase & 0,00019 & $-1,31$ & 5,6 & 27460 & $26,80 \%$ & 0 \\
\hline 3 & 6-*Yruvoyl-tetrahydropterin synthase/dimerization cofactor & $4,90 \mathrm{E}-07$ & $-1,75$ & 6,28 & 12035 & $29 \%$ & 0 \\
\hline 4 & Annexin A4 & 0,00032 & 1,99 & 5,4 & 36200 & $43,90 \%$ & 0 \\
\hline 5 & Bisphosphate 3'-nucleotidase 1 & 0,0047 & $-1,24$ & 5,5 & 33520 & $44,50 \%$ & 0 \\
\hline 6 & Carbonyl reductase 3 & $3,40 \mathrm{E}-07$ & $-3,56$ & 6,2 & 31330 & $18,80 \%$ & 0 \\
\hline 7 & Chaperonin subunit 2 (beta) & 0,0051 & 1,22 & 6 & 57800 & $38,70 \%$ & 0 \\
\hline 8 & Chromatin assembly factor 1 subunit C (CAF-1 subunit) & $2,40 \mathrm{E}-08$ & 1,85 & 4,95 & 52914 & $37,40 \%$ & 0 \\
\hline 9 & Protein 1 homolog gamma (HP1 gamma) & $1,10 \mathrm{E}-07$ & 2,41 & 5,13 & 21013 & $29,50 \%$ & 0 \\
\hline 10 & Chromogranin A precursor $(\mathrm{CgA})$ & $3,00 \mathrm{E}-07$ & 2,47 & 4,65 & 18571 & $41,60 \%$ & 0 \\
\hline 11 & Deoxyuridine triphosphatase & $4,00 \mathrm{E}-07$ & 1,41 & 5,7 & 17540 & $44,40 \%$ & 0 \\
\hline 12 & Endoplasmic reticulum protein ERp29 precursor & $8,90 \mathrm{E}-12$ & $-2,34$ & 5,9 & 28862 & $30,50 \%$ & 0 \\
\hline 13 & Enolase 1, alpha non-neuron & $2,10 \mathrm{E}-05$ & $-1,53$ & 6,4 & 47450 & $22,40 \%$ & 0 \\
\hline 14 & Galactose-4-epimerase, UDP & 0,00018 & $-2,86$ & 6,3 & 38550 & $19,50 \%$ & 0 \\
\hline 15 & Heat shock $70-k D a$ protein 5 (glucose-regulated protein) & $9,30 \mathrm{E}-07$ & $-2,91$ & 5 & 72520 & $40,60 \%$ & 0 \\
\hline 16 & High mobility group box 1 (Amphoterin) & $8,20 \mathrm{E}-10$ & 2,18 & 6,15 & 28573 & $24,70 \%$ & 0 \\
\hline 17 & Hypoxanthine guanine phosphoribosyl transferase & $6,60 \mathrm{E}-05$ & $-1,75$ & 6,21 & 24756 & $30,60 \%$ & 0 \\
\hline 18 & Malate dehydrogenase, cytoplasmic & $5,50 \mathrm{E}-06$ & $-1,61$ & 6,2 & 36630 & $20,10 \%$ & 0 \\
\hline 19 & Peroxiredoxin 4 & $1,10 \mathrm{E}-13$ & $-2,77$ & 6,67 & 31261 & $35,00 \%$ & 0 \\
\hline 20 & Phosphoglycerate mutase 1 & $2,00 \mathrm{E}-06$ & 2,95 & 6,7 & 28930 & $33,90 \%$ & 0 \\
\hline 21 & Prohibitin & 7,30E-05 & 1,31 & 5,6 & 29860 & $20,20 \%$ & 0 \\
\hline 22 & Prolyl 4-hydrolase, beta polypeptide;protein disulfide isomerase & $1,40 \mathrm{E}-07$ & $-2,44$ & 4,8 & 57440 & $40,90 \%$ & 0 \\
\hline 23 & Proteasome (prosome, macropain) subunit, alpha type 1 & 0,00018 & $-1,29$ & 6 & 29810 & $32,50 \%$ & 0 \\
\hline 24 & Proteasome (prosome, macropain) 28 subunit & 0,00015 & $-1,33$ & 5,5 & 28790 & $25,40 \%$ & 0 \\
\hline 25 & Protein phosphatase 1 , catalytic subunit, beta & 0,0019 & 1,25 & 5,8 & 37970 & $33,50 \%$ & 0 \\
\hline 26 & S-adenosylhomocysteine hydrolase & $2,60 \mathrm{E}-06$ & 1,45 & 6 & 48170 & $18,80 \%$ & 0 \\
\hline 27 & Stathmin 1 & $3,50 \mathrm{E}-05$ & 1,57 & 5,76 & 17205 & $47,70 \%$ & 0 \\
\hline 28 & Stromal cell -derived growth factor & $4,00 \mathrm{E}-10$ & $-2,28$ & 6,3 & 18080 & $28,00 \%$ & 0 \\
\hline 29 & Succinyl-CoA ligase [GDP-forming] beta chain & $9,80 \mathrm{E}-05$ & $-2,59$ & 5,8 & 44040 & $15,10 \%$ & 0 \\
\hline 30 & Superoxide dismutase 1 , soluble & $2,50 \mathrm{E}-08$ & $-1,97$ & 6 & 16100 & $44,00 \%$ & 0 \\
\hline 31 & Transaldolase 1 & 0,0048 & 1,5 & 6,6 & 37540 & $31,80 \%$ & 0 \\
\hline 32 & Tropomyosin alpha 3 chain & $3,40 \mathrm{E}-06$ & 1,53 & 4,7 & 32900 & $21,80 \%$ & 0 \\
\hline 33 & Ubiquitin thiolesterase & $1,70 \mathrm{E}-10$ & 2,98 & 5,14 & 25164 & $37,40 \%$ & 0 \\
\hline 34 & Ubiquinol-cytochrome-c-reductase complex core protein 1 & $2,80 \mathrm{E}-07$ & 1,6 & 5,8 & 53440 & $26,90 \%$ & 0 \\
\hline 35 & Glucose Regulated Protein 94 & $1,60 \mathrm{E}-06$ & $-2,73$ & 4,7 & 92041 & $16,80 \%$ & 0 \\
\hline
\end{tabular}

between the two images and statistical information. Statistical analysis and 3-D images were generated in the BVA module of DeCyder software. Representative
3-D images and statistical information displayed graphically for both ERp29 and peroxidoxin-4 are shown (Fig. 6). 
Glucose non-responsive high passage MIN-6 heta cell.

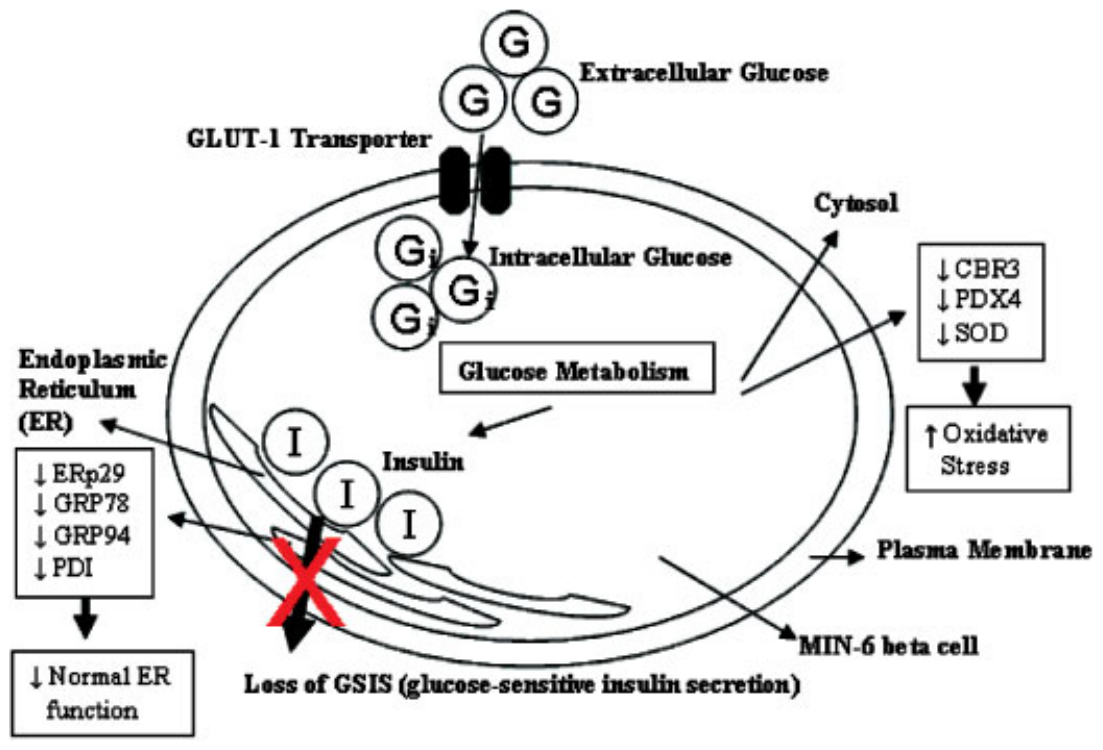

Figure 5. Diagram showing the subcellular location for ERp29 (endoplasmic reticulum protein 29), GRP78 (glucoserelated protein 78), GRP94 (glucoserelated protein 94), PDI, CBR3 (carbonyl reductase 3), PRDX4 (peroxidoxin 4), SOD1 (superoxide dismutase 1) and how decreased expression levels may contribute to a loss of GSIS (GlucoseSensitive Insulin Secretion) in glucose non-responsive $\mathrm{H}$ passage $\mathrm{MIN}-6$ beta cells.
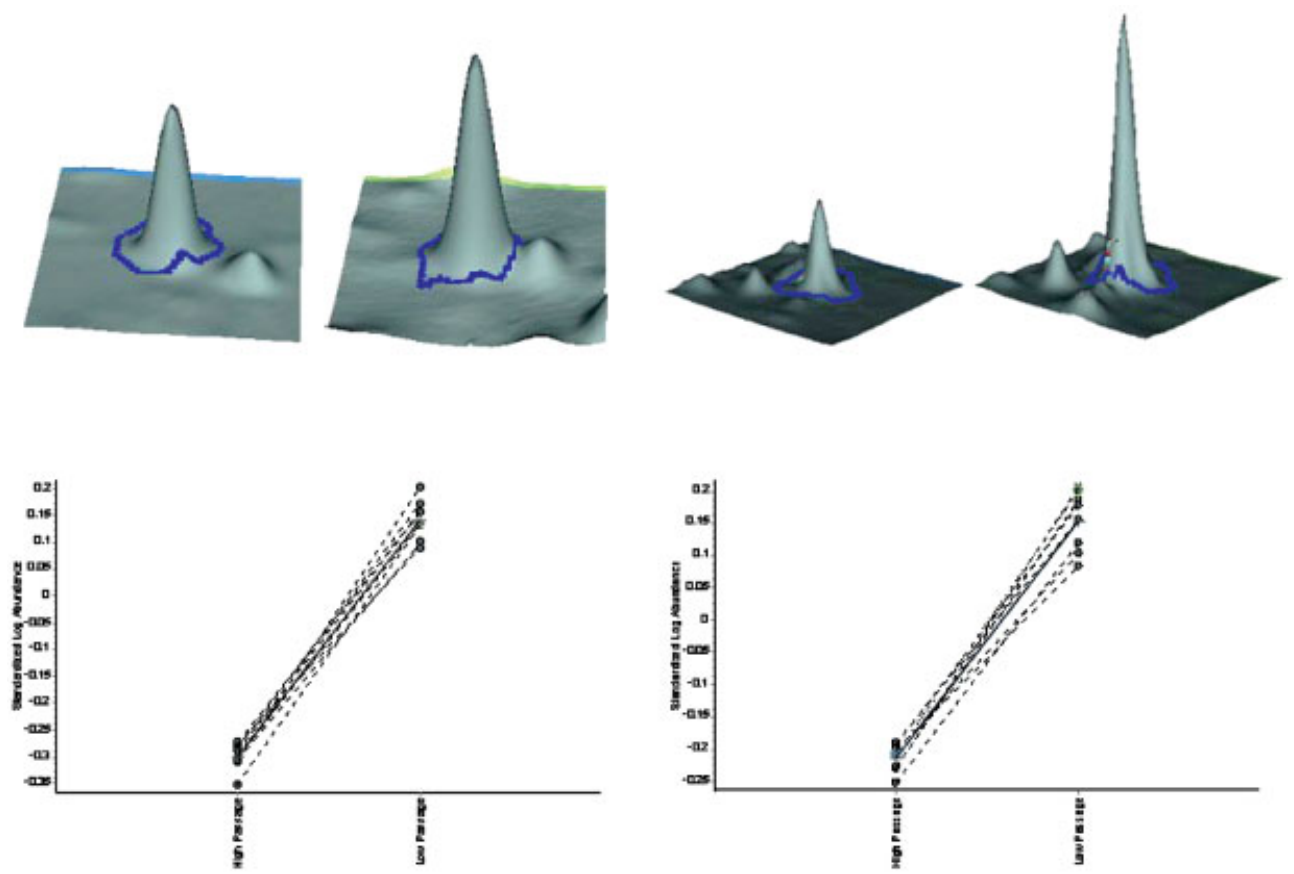

Figure 6. Statistical analysis and 3-D images for peroxidoxin-4 and endoplasmic reticulum protein (ERp29). Statistical analysis and 3-D images were generated in the BVA module of DeCyder software.

\section{Discussion}

As a possible alternative to - and improvement on - the existing therapies available for insulin-dependent diabetes, cultured beta cells offer enormous potential. However, for such cells to be considered an appropriate source of transplantable tissue, it is of fundamental importance that their secretion of insulin occurs in a regulated manner, in response to physiological changes in blood glucose levels.

The possibility of using isolated cultured beta cells in the treatment of diabetes has prompted this current study of differential protein expression between glucose-responsive and glucose non-responsive MIN-6 cells. A detailed under- 
standing, through proteomic analysis, of the complex processes involved in the loss of GSIS, found with passaging/ extended time in culture, may allow a greater insight into the mechanisms involved. The main techniques used in this study were 2D-DIGE and subsequent MS. The use of biological replicates from separately cultured cells allowed the application of stringent statistical analysis to generate a list of proteins displaying differential expression between $\mathrm{H}$ passage (glucose non-responsive; MIN-6(H)) and L passage (glucose responsive; MIN-6(L)) MIN-6 cells.

In our previous study of MIN-6 cells at passages 17 to 22, we established that MIN-6 is reproducibly glucose-responsive, secreting insulin in response to increased glucose levels. Following sub-culturing and continuous analysis of glucose-responsiveness at increasing passage numbers, we established that this response is completely lost by passage 40. Biological replicates selected for analysis in this study were, therefore, p18 (MIN-6(L); L passage; glucose-responsive) and p40 (MIN-6(H); high passage; glucose non-responsive) cells [5].

Contradictory results in recent times have been reported on the GSIS response of the murine beta-like cell line, MIN6. Some studies have reported the maintenance of GSIS while others have documented the loss of this response with increasing passage numbers and time in culture $[5,14,19$ 21]. Here, we report that L passage (passage 18) MIN-6 cells respond to changes in glucose concentration, producing an approximately 5.5 -fold GSIS in response to $26.7 \mathrm{mmol} / \mathrm{L}$, compared to $3.3 \mathrm{mmol} / \mathrm{L}$, glucose. After continuous culture to passage 40, this GSIS was no longer present. Beta cells play a central role in glucose homeostasis; therefore, beta cell loss or dysfunction leads to the development of diabetes.

Using LSCM analysis we observed that the presence of granules in similar numbers in the GSIS of both $\mathrm{H}$ and $\mathrm{L}$ passage MIN-6 cells suggests that the observed change in GSIS is not related to a deficiency in insulin capability. Phase contrast light microscopy indicates that MIN-6(L) cells that are glucose-responsive tend to grow closely together and form discrete colonies whereas MIN-6(H) cells, which have lost their glucose-responsiveness with culturing, appear to be more dispersed, stretched cells.

One of the characteristic features of beta cells is a highly developed ER, which is essential for proper insulin folding, packaging and secretion [22].The ER is one of the most important organelles, serving several important functions, including PTM, folding and assembly of newly synthesized secretory proteins (hormones, antibodies, pancreatic enzymes, etc.), and as a cellular calcium store. For proper functioning, a protein folds in a characteristic 3-D structure and may form a multimeric protein complex. The ER provides an environment perfectly suited for the folding and assembly of proteins. Efficient and rapid protein folding is assisted by molecular chaperones, folding factors and folding sensors. Molecular chaperones are proteins and protein complexes that bind to misfolded or unfolded polypeptide chains and affect the subsequent folding processes of these chains. Chaperones are found in all types of cells and cellular compartments, and have a wide range of binding specificities and functional roles.

One of the most significant findings of the study reported here was the differential expression of major proteins associated with the ER, namely ERp29-, GRP78, GRP94- and PDI, all of which have very similar or complementary functions at the ER, especially in protein folding, disulphide bond formation, PTM and protein secretion.

ERp29, characterised initially in 1997 [23], is a major resident of the ER that seemingly plays an important role in most animal cells [24, 25]. The expression of ERp29 reaches its highest levels in secretory cells; seems to play an important role in protein folding; consists of two domains of which the N-terminal domain of ERp29 resembles the thioredoxin module of PDI [26]; and has been shown to associate with GRP78 and GRP94 [27]. Recently, Morand et al. [11] profiled hepatic ER-associated proteins from control and fructose-fed (insulin-resistant) hamsters using 2-DE and MS and found ERp29 to be 4.5-fold down-regulated in fructose-fed hamster livers. In our study, we found ERp29 to be significantly decreased in MIN-6(H) cells compared to MIN-6(L) cells that maintain their GSIS.

Protein profiling of human pancreatic islets by 2-DE and MS found $23 \%$ of the proteins identified to be molecular chaperones, including GRP78 and GRP94 [28]. GRP78 is an abundant ER protein and was originally identified as a retention factor for unassembled IgG heavy chains in the ER [29, 30]. Cycles of ATP binding and hydrolysis regulate substrate binding and release from GRP78 [31], which is now recognized as a key chaperone with multiple roles in ER quality control, for example the translocation and folding of proteins [32, 33]. The abundant soluble ER-resident GRP94 [34, 35], also provides chaperone and folding facilitation in the ER. Both GRP78 and GRP94 have previously been implicated in the pathophysiology of diabetes. Wang et al. [36] observed that BiP (GRP78) formed complexes with wild-type proinsulin expressed in $\mathrm{CHO}$ cells. This suggests that this association may occur physiologically in pancreatic beta cells; however, this warrants further investigation. Expression of GRP78 and GRP94 is induced by the presence of unfolded or unassembled protein subunits within the ER [37-39]. A 2.73- and a 2.91-fold decrease in GRP78 and GRP94, respectively, in the glucose nonresponsive MIN-6(H) cells suggests that the ER of this phenotype does not intrinsically contain the same protein folding/handling/secretory power as in the unaffected glucose responsive MIN-6(L) passage phenotype. Many groups have published data linking the roles of GRP78 and GRP94 with the pathogenesis of diabetes $[6,8]$. Our data points to a "winding down" of a fully operational ER and hence may partially explain the loss of GSIS associated with continual culture of MIN-6 cells. Beta cells are extremely specialised cells adapted for glucose sensing and insulin secretion, thus any disruption to this highly specific process will compromise its position in maintaining 
homeostasis. Together with ERp29, GRP78 and GRP94, PDI is an intrinsic member of the ER with numerous dedicated functions and characteristics.

The correct arrangement of disulphide bonds is important for the proper stability and function of many proteins. PDI is the enzyme responsible for catalyzing efficient formation of native disulphide pairings in eukaryotic cells. PDI is an ER-resident protein that catalyzes the oxidation of dithiols and the reduction and isomerization of disulphide bonds in secretory proteins. Of importance to diabetes is that PDI is now regarded as an insulin-regulated gene [40, 41]. The loss of GSIS associated with H passage MIN-6 beta cells coincides with a significant decrease in the abundance levels of PDI. DIGE analysis of cell lysates from MIN-6 glucose responsive and glucose non-responsive beta cells reveals a 2.44-fold decrease in PDI in the glucose non-responsive phenotype.

Several models of diabetes have displayed a link to the ER proteins identified in this study, namely ERp29, GRP78, GRP94 and PDI. All these proteins have very similar or complementary functions at the ER, especially with respect to protein folding, bond formation, PTM and protein secretion. From the data presented here, continuous culture of MIN-6 cells results in the appearance of phenotypic changes. Most notably, deviation from characteristic MIN-6 morphology, growth patterns, loss of GSIS and a significant reduction in the expression levels in ERp29, GRP78, GRP94 and PDI. Therefore, it seems that the inability of the glucose nonresponsive phenotype to secrete insulin in response to appropriate stimuli is intrinsically linked with the differential regulation of the ER proteins in question.

Oxidative stress, defined as a persistent imbalance between the production of highly reactive molecular species (chiefly oxygen and nitrogen) and antioxidant defences is likely involved in progression of pancreatic beta cell dysfunction and is possibly caused by low levels of antioxidant enzyme expressions, therefore making pancreatic beta cells more vulnerable. Oxidative stress results from increased content of ROS and/or RNS. Superoxide anions and the hydroxyl radical are examples of charged ROS, with hydrogen peroxide $\left(\mathrm{H}_{2} \mathrm{O}_{2}\right)$ being an example of an uncharged species [42]. Maechler et al. [13] showed that oxygen stress generated by short exposure of beta cell preparations to $\mathrm{H}_{2} \mathrm{O}_{2}$ increases production of p21 and decreases insulin mRNA, cytosolic ATP, and calcium flux in cytosol and mitochondria, and causes apoptosis. They showed as well that the mitochondria is a primary targets for hydrogen peroxide $\left(\mathrm{H}_{2} \mathrm{O}_{2}\right)$ damage, which will eventually interrupt the transduction of signals normally coupling glucose metabolism to insulin secretion.

Beta cells are sensitive to ROS and RNS because they are low in free radical quenching (antioxidant) enzymes such as catalase, glutathione peroxidase, and superoxide dismutase [43]. In this study, we found that the expression levels of carbonyl reductase 3 , superoxide dismutase 1 and peroxiredoxin 4 to be significantly decreased in MIN-6(H) compared to MIN-6(L) cells, which was associated with the loss of GSIS.
The decrease in abundance levels of these already low expressed antioxidant enzymes suggests that the $H$ passage MIN-6 cells have little ability to counteract the damaging affect of free radicals and that this may have an impact on insulin secretion. Tiedge et al. [12] showed that the effects of stable overexpression of glutathione peroxidase (Gpx), catalase (Cat), or $\mathrm{Cu} / \mathrm{Zn}$ superoxide dismutase (SOD) can protect insulin-producing RINm5F cells against oxidative damage. In addition, the adenovirus-mediated catalase gene transfer was also shown to reduce oxidant stress in human, porcine and rat pancreatic islets [44].

From the data presented here, it is clear that loss of GSIS is associated with a reduction in expression levels of freeradical quenching (antioxidant) enzymes such as carbonyl reductase 3, superoxide dismutase 1 and peroxiredoxin 4 . Recently, it was shown that chronic high glucose culture caused impairment in glucose-sensitive insulin secretion in DBA/2 islets, which have a genetic predisposition to failure, and this may be the result of oxidative stress [45].

To conclude, we have identified 35 proteins differentially expressed between glucose-responsive and glucose nonresponsive MIN-6 beta cells. Proteins associated with ER functioning and oxidative stress were found to be particularly affected. The results shown in this study suggest that shorter culture times and a greater understanding of the protein expression changes associated with the loss of GSIS in $\mathrm{H}$ passage MIN-6 beta cells will contribute to the ultimate goal of developing cell-based transplantation therapy for insulindependent diabetes.

This work was supported by the PRTLI CYcle 3 Programme of the Irish Higher Education Authority.

\section{References}

[1] Zimmet, P., Alberti, K. G., Shaw, J., Nature 2001, 414, 782787.

[2] Gale, A. E. M., Diabetologia 2005, 48, 2445-2450.

[3] Shapiro, A. M., Lakey, J. R., Ryan, E. A., Korbutt, G. S. et al., N. Engl. J. Med. 2000, 343, 230-238.

[4] Scharfmann, R., Eur. J. Clin. Invest. 2003, 33, 595-600.

[5] O'Driscoll, L., Gammell, P., Clynes, M., Transplant. Proc. 2004, 36, 1159-1162.

[6] Wang, J., Takeuchi, T., Tanaka, S., Kubo, S. K. et al., J. Clin. Invest. 1999, 103, 27-37.

[7] Sitia, R., Braakman, I., Nature 2003, 426, 891-894.

[8] Nozaki, J., Kubota, H., Yoshida, H., Naitoh, M. et al., Genes Cells 2004, 9, 261-270.

[9] Lan, H., Rabaglia, M. E., Schueler, K. L., Mata, C. et al., Diabetes 2004, 53, 240-244.

[10] Nardai, G., Stadler, K., Papp, E., Korcsmaros, T. et al., Biochem. Biophys. Res. Commun. 2005, 334, 787-795.

[11] Morand, J. P., Macri, J., Adeli, K., J. Biol. Chem. 2005, 280, 17626-17633. 
[12] Tiedge, M., Lortz, S., Drinkgern, J., Lenzen, S., Diabetes $1997,46,1733-1742$.

[13] Maechler, P., Jornot, L., Wollheim, C. B., J. Biol. Chem. 1999, 274, 27905-27913.

[14] Miyazaki, J., Araki, K., Yamato, E., Ikegami, H. et al., Endocrinology 1990, 127, 126-132.

[15] Lilla, V., Webb, G., Rickenbach, K., Maturana, A. et al., Endocrinology 2003, 144, 1368-1379.

[16] Zhang, B., Hosaka, M., Sawada, Y., Torii, S. et al., Diabetes 2003, 52, 2720-2730.

[17] Alban, A., David, S. O., Björkesten, L., Andersson, C. et al., Proteomics 2003, 3, 36-44.

[18] Westermeier, R., Naven, T., Practical Proteomics, WileyVCH-Verlag, Weinheim, Germany 2002.

[19] Kayo, T., Sawada, Y., Suzuki, Y., Suda, M. et al., J. Biol. Chem. 1996, 271, 10731-10737.

[20] Ishihara, H., Asano, T., Tsukuda, K., Katagiri, H. et al., Am. J. Physiol. 1995, 269, 897-902.

[21] Kinoshita, N., Echigo, Y., Shinohara, S., Gu, Y. J. et al., Cell Transplant. 2001, 10, 473-477.

[22] Oyadomari, S., Araki, E., Mori, M., Apoptosis 2002, 7, 335345.

[23] Demmer, J., Zhou, C. M., Hubbard, M. J., FEBS Lett. 1997, 402, 145-150.

[24] Hubbard, M. J., Proteomics 2002, 2, 1069-1078.

[25] Hermann, V. M., Cutfield, J. F., Hubbard, M. J., J. Biol. Chem. 2005, 280, 13529-13537.

[26] Knoblach, B., Keller, B. O., Groenendyk, J., Aldred, S. et al., Mol. Cell. Proteomics 2003, 2, 1104-1119.

[27] Sargsyan, E., Baryshev, M., Szekely, L., Sharipo, A., Mkrtchian, S., J. Biol. Chem. 2002, 277, 17009-17015.

[28] Ahmed, M., Forsberg, J., Bergsten, P., J. Proteome Res. 2005, 4, 931-940.
[29] Bole, D. G., Hendershot, L. M., Kearney, J. F., J. Cell. Biol. 1986, 102, 1558-1566.

[30] Haas, I. G., Wabl, M., Nature 1983, 306, 387-389.

[31] Pelham, H. R., Cell 1986, 46, 959-961.

[32] Johnson, A. E., van Waes, M. A., Rev. Cell. Dev. Biol. 1999, $15,799-842$.

[33] Rapoport, T. A., Matlack, K. E. S., Plath, K., Misselwitz, B., Staeck, O., J. Biol. Chem. 1999, 380, 1143-1150.

[34] Melnick, J., Aviel, S., Argon, Y., J. Biol. Chem. 1992, 267, 21303-21306.

[35] Melnick, J., Dul, J. L., Argon, Y., Nature 1994, 370, 373-375.

[36] Yoshioka, M., Kayo, T., Ikeda, T., Koizumi, A., Diabetes 1997, 46, 887-894.

[37] Kozutsumi, Y., Segal, M., Normington, K., Gething, M. J., Sambrook, J., Nature 1988, 332, 462-464.

[38] Dorner, A. J., Wasley, L. C., Kaufman, R. J., J. Biol. Chem. 1989, 264, 20602-20607.

[39] Lee, A. S., Curr. Opin. Cell. Biol. 1992, 4, 267-273.

[40] Nieto, A., Mira, E., Castano, J. G., Biochem. J. 1990, 267, $317-$ 323.

[41] O'Brien, R. M., Granner, D. K., Physiol. Rev. 1996, 76, 1109 1161.

[42] Rosen, P., Nawroth, P. P., King, G., Moller, W. et al., Diabetes Metab. Res. Rev. 2001, 17, 189-212.

[43] Tiedge, M., Lortz, S., Munday, R., Lenzen, S., Diabetes 1998, 47, 1578-1585.

[44] Benhamou, P. Y., Moriscot, C., Richard, M. J., Beatrix, O. et al., Diabetologia 1998, 41, 1093-1100.

[45] Zraika, S., Aston-Mourney, K., Laybutt, D. R., Kebede, M. et al., Diabetologia 2006, (pub. ahead of press). 